\title{
The driving effects of urbanization on economic growth and water use change in China:
}

\section{A provincial-level analysis in 1997-2011}

\author{
BAO Chao ${ }^{1,2,3}$, CHEN Xiaojie ${ }^{1,2,3}$
}

1. Institute of Geographic Sciences and Natural Resource Research, CAS, Beijing 100101, China;

2. Key Laboratory of Regional Sustainable Development Modeling, CAS, Beijing 100101, China;

3. University of Chinese Academy of Sciences, Beijing 100049, China

\begin{abstract}
As one of the key issues in China's sustainable development, rapid urbanization and continuous economic growth are accompanied by a steady increase of water consumption and a severe urban water crisis. A better understanding of the relationship among urbanization, economic growth and water use change is necessary for Chinese decision makers at various levels to address the positive and negative effects of urbanization. Thus, we established a complete decomposition model to quantify the driving effects of urbanization on economic growth and water use change for China and its 31 provincial administrative regions during the period of 1997-2011. The results show that, (1) China's urbanization only contributed about $30 \%$ of the economic growth. Therefore, such idea as urbanization is the major driving force of economic growth may be weakened. (2) China's urbanization increased $2352 \times 10^{8} \mathrm{~m}^{3}$ of water use by increasing the economic aggregate. However, it decreased $4530 \times 10^{8} \mathrm{~m}^{3}$ of water use by optimizing the industrial structure and improving the water use efficiency. Therefore, such idea as urbanization is the major driving force of water demand growth may be reacquainted. (3) Urbanization usually made greater contribution to economic and water use growth in the provincial administrative regions in east and central China, which had larger population and economic aggregate and stepped into the accelerating period of urbanization. However, it also made greater contribution to industrial structure optimization and water use efficiency improvement, and then largely decreased total water use. In total, urbanization had negative effects on water use growth in most provincial administrative regions in China, and the spatiotemporal differences among them were lessened on the whole. (4) Though urbanization helps to decrease water use for China and most provincial administrative regions, it may cause water crisis in urban built-up areas or urban agglomerations. Therefore, China should construct the water transfer and compensation mechanisms between urban and rural areas, or low and high density urban areas as soon as possible.
\end{abstract}

Keywords: urbanization; economic growth; water demand; complete decomposition model; spatiotemporal difference; water resources compensation

Received: 2014-01-22 Accepted: 2014-07-30

Foundation: National Social Science Foundation of China, No.13\&ZD027; National Natural Science Foundation of China, No.41101538

Author: Bao Chao (1978-), PhD and Associate Professor, specialized in urbanization and urban sustainable development. E-mail: baoc@igsnrr.ac.cn 


\section{Introduction}

Urbanization is a dynamic process of relocating the population from relatively low density rural areas to very high density urban areas, with a transformation from an agricultural based economy to the manufacturing workshop (Bao and Fang, 2012). Generally speaking, it contains population urbanization, economic urbanization, social urbanization, and land urbanization (Bao and Fang, 2009). Among these processes, population urbanization, which is defined by the change process of urban and rural population structure, is the most basic and core connotation of urbanization. It directly promotes economic and land urbanization, i.e., it makes urban areas occupy a larger proportion of economic aggregate and land resources in a specific area. Then it makes various urbanization processes interact with each other.

Wide and deep research on urbanization has been carried out by scholars from geography, economics, demography, sociology and other fields in China and abroad (Liu et al., 2005). At the same time, as the population and economic scale gradually approached or exceeded the water resources carrying capacity in China, the relationships among urbanization, economic growth and water resources sustainable utilization have been a hot research topic since the late 1990s (Bao and Fang, 2007). Some scholars considered that urbanization is the engine and major driving force of economic growth (Bertinelli and Black, 2004). Urbanization and economic growth were considered as the major causes of water crisis because they bring more water resources demand (Jenerette and Larsen, 2006). Moreover, this kind of water crisis may be more serious than farmland decline due to land urbanization (Brown, 2001). However, some scholars considered that urbanization may not be the direct driving force of economic growth (Lin et al., 2013). Even some scholars considered that the growth of cities or large cities may reduce the growth of rural areas or small and medium-sized towns, and make the economic growth of the whole region unable to reach the maximum (Chen and Partridge, 2013). Besides, through the research on the relationship between urbanization stages and water resources utilization stages (Merrett, 1997), and the relationship between economic growth and water use change (Jia et al., 2004), some scholars revealed the regular pattern of zero growth of water demand. It lessened the public fear of water crisis to some extent.

In China, from 1980 (the initial stage of the reform and opening policy) to 2011, the population urbanization level had increased from $19.4 \%$ to $51.3 \%$. The ratio of non-agricultural added values to GDP had increased from $69.9 \%$ to $90.0 \%$. GDP had increased from 451.8 billion yuan to 8312.4 billion yuan (constant price in 1980). The total water use had increased from $4437 \times 10^{8} \mathrm{~m}^{3}$ to $5965 \times 10^{8} \mathrm{~m}^{3}$ (not including eco-water). Related statistical data showed that the relationship between urbanization level and economic development level could be expressed by a logarithmic curve (Zhou, 1995). Total water use and economic development level could be expressed by a power function curve (Song et al., 2004). Urbanization level and total water use could be expressed by a logarithmic curve (Bao and Fang, 2006). That is to say, with the increase of the urbanization level, China's economic aggregate and total water use had also significantly increased.

However, related mechanism analysis showed that urbanization has both positive and negative effects on water resources utilization. Moreover, water resources utilization can sustain and constrain the urbanization process at the same time (Bao and Fang, 2010). The practice in many countries and regions showed that even if the urbanization level does not 
increase or even decreases, the economic aggregate may still increase. Even if the urbanization level and economic aggregate grow fast, total water use may increase slowly or even decrease. In addition, empirical analyses of some typical research areas showed that the population-economic urbanization may reduce the total water use (Bao, 2012; Zhang et al., 2011). Thus, it is clear that urbanization, economic growth and water use change are not necessarily the cause and consequence. There may be different characteristics at different stages and in different regions.

During the stage of rapid urbanization, is urbanization an important cause of economic growth and water use increase? Do urbanization and economic growth have positive or negative impact on total water use increase? How much is the positive or negative impact? Is there a consistent change in different spatiotemporal scopes? Such questions are all desiderated to scientific explanations. Therefore, we established a complete decomposition model to quantify the driving effects of urbanization on economic growth and water use change in China and its 31 provincial administrative regions (not including Hong Kong, Macao and Taiwan) in 1997-2011. It may help to correct the misunderstandings of the past about the relationships among urbanization, economic growth and water use change at national and provincial level in China.

\section{Methodology and data sources}

\subsection{The complete decomposition model to quantify the driving effects of urbanization on economic growth and water use change}

Complete and incomplete decomposition models are both important methods to determine driving factors. Both of them have various and specific calculation methods (Ang and Zhang, 2000). However, the complete decomposition model can completely eliminate the residuals. It has been applied in some fields such as energy, eco-environment and water resources (Sun, 1998; Ang and Zhang, 2000; Liu et al., 2008; Sun and Wang, 2010; Zhang et al., 2011). In these studies, the effects of economic growth, industrial structure change and technical efficiency improvement on resources and environmental changes have been characterized. According to the models mentioned above, a complete decomposition model to measure the driving effects of urbanization on water use change has been established and applied in Zhangye City, which is a typical oasis city in the Heihe River Basin in Northwest China (Bao, 2012). However, population urbanization and economic urbanization were regarded as two independent processes in this model. The direct impacts of population urbanization and economic urbanization on total water use change were calculated individually. Therefore, further improvements of this model are given as follows:

Taking the economic aggregate $(E)$ as an interaction result of population scale $(P)$, urban and rural population structure (expressed as the percentage of urban or rural population in total population, $S_{i}$ ) and per capita GDP (expressed as urban or rural per capita GDP, $I_{i}$ ), thus the economic aggregate change can be decomposed into population scale effect $\left(P_{\text {eff }}\right)$, population structure effect $\left(S_{\text {eff }}\right)$ and per capita economic efficiency effect $\left(I_{\text {eff }}\right)$.

$$
E=P \times \sum_{i} S_{i} I_{i}
$$

Assuming the indexes of the base period and the end period with a superscript of 0 and $t$ 
respectively, thus the economic aggregates of the base and end period can be expressed as $E^{0}$ and $E^{t}$ (We set $t=1$ in this paper). The economic aggregate change $\Delta E(\Delta P, \Delta S$ and $\Delta I$ as the same) in $t$ years is:

$$
\Delta E=E^{t}-E^{0}
$$

The contributions of the changes of factor $P, S$, and $I$ to $\Delta E$ are given as follows:

$$
\begin{aligned}
& P_{\text {eff }}=\Delta P \sum_{i} I_{i}^{0} S_{i}^{0}+\frac{1}{2} \Delta P \sum_{i}\left(I_{i}^{0} \Delta S_{i}+S_{i}^{0} \Delta I_{i}\right)+\frac{1}{3} \Delta P \sum_{i} \Delta I_{i} \Delta S_{i} \\
& S_{\text {eff }}=P^{0} \sum_{i} I_{i}^{0} \Delta S_{i}+\frac{1}{2} \sum_{i} \Delta S_{i}\left(I_{i}^{0} \Delta P+P^{0} \Delta I_{i}\right)+\frac{1}{3} \Delta P \sum_{i} \Delta I_{i} \Delta S_{i} \\
& I_{\text {eff }}=P^{0} \sum_{i} S_{i}^{0} \Delta I_{i}+\frac{1}{2} \sum_{i} \Delta I_{i}\left(S_{i}^{0} \Delta P+P^{0} \Delta S_{i}\right)+\frac{1}{3} \Delta P \sum_{i} \Delta I_{i} \Delta S_{i}
\end{aligned}
$$

If $P_{\text {eff }}, S_{\text {eff }}$ and $I_{\text {eff }}$ are positive respectively, the changes of population scale, population structure and per capita economic efficiency will increase the economic aggregate. On the contrary, if $P_{\text {eff }}, S_{\text {eff }}$ and $I_{\text {eff }}$ are negative, the changes of population scale, population structure and per capita economic efficiency will decrease the economic aggregate.

The economic aggregate change $\Delta E$ is the sum of the three kinds of composition effects:

$$
\Delta E=P_{\text {eff }}+S_{\text {eff }}+I_{\text {eff }}
$$

where $S_{\text {eff }}$ is interpreted as the direct driving effect of population urbanization on economic aggregate change. $\Delta E, P_{\text {eff, }}, S_{\text {eff }}$ and $I_{\text {eff }}$ are absolute amounts of economic aggregate change, so the results are comparable and cumulative in time series, i.e. the sum of the economic aggregate change from year $t_{1}$ to year $t_{2}$ and that from year $t_{2}$ to year $t_{3}$ is equivalent to that from year $t_{1}$ to year $t_{3}\left(P_{\text {eff }}, S_{\text {eff }}\right.$ and $I_{\text {eff }}$ as the same).

$$
\Delta E^{t_{1}-t_{3}}=\Delta E^{t_{1}-t_{2}}+\Delta E^{t_{2}-t_{3}}
$$

According to the above principles, the complete decomposition of per capita economic efficiency can be expressed as the following formula:

$$
I=\sum_{i} S_{i} I_{i}
$$

The change of per capita economic efficiency $\Delta I$ can be decomposed into direct technical efficiency effect $\left(I I_{\text {eff }}\right)$ and indirect structure effect $\left(I S_{\text {eff }}\right.$, which is interpreted as the driving effect of population urbanization on the change of per capita economic efficiency). They are also comparable and cumulative in time series:

$$
\begin{gathered}
I I_{\text {eff }}=\sum_{i} S_{i}^{0} \Delta I_{i}+\frac{1}{2} \sum_{i} \Delta I_{i} \Delta S_{i} \\
I S_{\text {eff }}=\sum_{i} I_{i}^{0} \Delta S_{i}+\frac{1}{2} \sum_{i} \Delta I_{i} \Delta S_{i} \\
\Delta I=I S_{\text {eff }}+I I_{\text {eff }}
\end{gathered}
$$

The indirect driving effect of population urbanization on economic aggregate change through influencing the change of per capita economic efficiency $\left(S I_{e f f}\right)$ is:

$$
S I_{\text {eff }}=I_{\text {eff }} \times I S_{\text {eff }} / \Delta I
$$

The direct and indirect driving effect of population urbanization on economic aggregate change $\left(U_{e f f}\right)$ is: 


$$
U_{e f f}=S_{e f f}+S I_{e f f}
$$

In the same way, total water use $(W)$ can be regarded as the interaction result of economic scale $(E)$, urban and rural economic structure (expressed as the percentages of urban or rural GDP in total GDP, $E S_{i}$ ) and water use efficiency (expressed as urban or rural water use per 10,000 yuan GDP, $\left.E I_{i}\right)$. Thus, total water use change $(\Delta W)$ can be decomposed into economic scale effect $\left(E P_{\text {eff }}\right)$, economic structure effect $\left(E S_{\text {eff }}\right.$, which is interpreted as the direct driving effect of economic urbanization on total water use change) and water use efficiency effect $\left(E I_{e f f}\right)$. The change of water use efficiency $(\Delta E I)$ can be decomposed into direct technical efficiency effect $\left(E I I_{\text {eff }}\right)$ and indirect structure effect $\left(E I S_{\text {eff, }}\right.$, which is interpreted as the driving effect of economic urbanization on the change of water use efficiency). The indirect driving effect of economic urbanization on total water use change through influencing water use efficiency is marked as $E S I_{\text {eff }}$. The direct and indirect driving effect of economic urbanization on total water use change is marked as $E U_{\text {eff }}$ (the sum of $E S_{\text {eff }}$ and $E S I_{\text {eff }}$ ). The calculation methods of these variables are just the same as formulas (1)-(13).

From the comprehensive perspective of the population-economic urbanization process, there are three ways in which the urbanization process leads to total water use change $(\Delta W U)$. The first is the direct driving effect of economic urbanization on total water use change $\left(E S_{\text {eff }}\right)$. The second is the indirect driving effect of economic urbanization on total water use change through influencing water use efficiency $\left(E S I_{e f f}\right)$. The third is the driving effect of $U_{\text {eff }}$ on total water use change, which is marked as $Q E P_{\text {eff. }}$.

$$
\begin{gathered}
Q E P_{\text {eff }}=E P_{\text {eff }} \times U_{\text {eff }} / \Delta E \\
\Delta W U=E S_{\text {eff }}+E S I_{e f f}+Q E P_{e f f}
\end{gathered}
$$

\subsection{Basic data sources and interpretation}

The complete decomposition model to quantify the driving effects of urbanization on economic growth and water use change needs nine variables as basic data, such as total population, urban population, rural population, GDP, urban GDP, rural GDP, total water use, urban water use and rural water use. National and provincial data can be directly or indirectly obtained from China Statistic Yearbook and China Water Resources Bulletin. As China Water Resources Bulletin has been compiled every year since 1997 and China has stepped into the stage of rapid urbanization since 1996 (Fang et al., 2009), we chose the period of 1997-2011 as our research period for the availability of data and the typicality of research period.

As the population data from China Statistic Yearbook (including China's population census data of 6 times) have poor comparability among different regions and times (Zhou and $\mathrm{Yu}, 2002)$, Shen (2006) modified the total population and urban population from 1982 to 2000 in China and its 31 provincial administrative regions. Based on Shen's research, Fang et al. (2009) extended the data series to 2005 and established logistic models to predict the future blueprint. For higher comparability, the population data in 1997-2005 were adopted directly from which Fang et al. modified, and the population data in 2006-2011 were adopted from which Fang et al. predicted.

For economic data, according to the growth rates compared to the prior year, we converted all the added values of the primary, secondary and tertiary industries from 1997 to 2011 in China and its 31 provincial administrative regions to constant price in 1997. Then 
we added up them to obtain GDP. As the economic aggregates of urban and rural areas are difficult to acquire, we used the sum of the converted added values of the secondary and tertiary industries to replace urban GDP, and used the converted added values of the primary industry to replace rural GDP.

In the aspect of water use data, according to China Water Resources Bulletin, total water use is divided into six categories, such as water consumption for farmland irrigation, water consumption for forestry \& fishery \& animal husbandry, domestic water for rural residents, water consumption for industry, urban public water, domestic water for urban residents (water consumption for urban and rural eco-environment provided by artificial measures was not included in this paper). The previous three categories were summed up to rural water use, and the last three categories were summed up to urban water use.

\section{Results}

Based on the above methodology and data sources, we quantified the driving effects of population urbanization on economic growth for China and its 31 provincial administrative regions during the period of 1997-2011, and analyzed the spatiotemporal characteristics. Subsequently, we quantified the driving effects of population-economic urbanization on water use change and analyzed the spatiotemporal characteristics.

\subsection{Spatiotemporal characteristics of the driving effects of population urbanization on economic growth in China}

3.1.1 Driving effects of China's population urbanization on economic growth and its dynamic change

China's economic aggregate had an increasing trend over the period of 1997-2011 as all $\Delta E$ $>0$ (Table 1). Moreover, the increments of GDP compared to the prior year $(\Delta E)$ also had an increasing trend except that they fluctuated slightly since 2008. From 1997 to 2011, China's GDP increased $20.385 \times 10^{12}$ yuan in total. The average annual growth rate was $9.85 \%$. Specifically, the increment of GDP caused by the population scale effect $\left(P_{\text {eff }}\right)$ was $1.491 \times 10^{12}$ yuan, and the contribution rate was $7.3 \%$. The increment of GDP caused by per capita economic efficiency effect $\left(I_{e f f}\right)$ was $15.330 \times 10^{12}$ yuan, and the contribution rate was $75.2 \%$. The increment of GDP caused by the direct effect of population urbanization $\left(S_{\text {eff }}\right)$ was $3.564 \times 10^{12}$ yuan, and the contribution rate was $17.5 \%$. It showed that the improvement of per capita economic efficiency was the most important cause of the continuous economic growth in China, while population urbanization and population growth had a relatively low priority for China's economic growth.

China's per capita economic efficiency also had an increasing trend as all $\Delta I>0$ (Table 1), from 6106 yuan per capita in 1997 to 20,452 yuan per capita in 2011. China's per capita economic efficiency increased 14346 yuan per capita in total. The average annual growth rate was $9.02 \%$. Specifically, the increment of per capita economic efficiency caused by the direct technical efficiency effect $\left(I I_{\text {eff }}\right)$ was 11,637 yuan per capita, and the contribution rate was $81.1 \%$. The increment of per capita economic efficiency caused by the indirect effect of population urbanization $\left(I S_{\text {eff }}\right)$ was 2709 yuan per capita, and the contribution rate was $18.9 \%$. Thus, we can calculate that the indirect driving effect of population urbanization on 
economic aggregate change through influencing the change of per capita economic efficiency $\left(S I_{e f f}\right)$ was $2.872 \times 10^{12}$ yuan, and the direct and indirect driving effect of population urbanization on economic aggregate change $\left(U_{\text {eff }}\right)$ was $6.436 \times 10^{12}$ yuan. The comprehensive contribution rate of population urbanization to economic growth during the period of 1997-2011 was 31.6\%.

Table 1 Driving effects of China's population urbanization on economic growth from 1997 to 2011

\begin{tabular}{cccccccccccccccc}
\hline Year & 1998 & 1999 & 2000 & 2001 & 2002 & 2003 & 2004 & 2005 & 2006 & 2007 & 2008 & 2009 & 2010 & 2011 & $1997-2011$ \\
\hline$\Delta E$ & 586 & 614 & 732 & 781 & 925 & 1114 & 1233 & 1523 & 1900 & 2391 & 1857 & 1947 & 2411 & 2369 & 20385 \\
$P_{\text {eff }}$ & 68 & 90 & 137 & 75 & 65 & 68 & 98 & 92 & 126 & 120 & 128 & 134 & 141 & 149 & 1491 \\
$I_{\text {eff }}$ & 421 & 434 & 400 & 576 & 692 & 855 & 912 & 1170 & 1398 & 1963 & 1389 & 1448 & 1876 & 1797 & 15330 \\
$S_{\text {eff }}$ & 97 & 91 & 195 & 131 & 169 & 191 & 223 & 261 & 376 & 308 & 340 & 365 & 394 & 424 & 3564 \\
$S I_{\text {eff }}$ & 79 & 75 & 131 & 107 & 136 & 156 & 179 & 213 & 296 & 266 & 273 & 291 & 325 & 343 & 2872 \\
$U_{\text {eff }}$ & 176 & 166 & 326 & 238 & 305 & 348 & 402 & 474 & 672 & 574 & 613 & 656 & 719 & 768 & 6436 \\
$\Delta I$ & 421 & 422 & 473 & 555 & 672 & 812 & 875 & 1095 & 1347 & 1713 & 1296 & 1350 & 1680 & 1635 & 14346 \\
$I I_{\text {eff }}$ & 342 & 349 & 318 & 452 & 540 & 663 & 703 & 896 & 1062 & 1481 & 1041 & 1078 & 1389 & 1322 & 11637 \\
$I S_{\text {eff }}$ & 79 & 73 & 155 & 103 & 132 & 148 & 172 & 200 & 285 & 232 & 255 & 272 & 291 & 312 & 2709 \\
\hline
\end{tabular}

Note: The units of $\Delta E, P_{e f f}, I_{e f f}, S_{e f f}, S I_{e f f}$, and $U_{e f f}$ are billion yuan; the units of $\Delta I, I I_{e f f}$, and $I S_{e f f}$ are yuan per capita.

From 1997 to 2011, the driving effect of population growth on economic growth $\left(P_{e f f}\right)$ was relatively small (Table 1 ). The driving effect of per capita economic efficiency on economic growth $\left(I_{e f f}\right)$ was relatively large, and the contribution rates stayed between $70 \%$ and $75 \%$ in most years. The direct contribution rates of population urbanization to economic growth mainly stayed between $15 \%$ and $20 \%$, while the comprehensive contribution rates stayed around $30 \%$. On the whole, population urbanization had positive driving effect on economic growth. However, this kind of effect should not be overstated, because more than $60 \%$ of China's economic growth relied on the improvement of direct technical efficiency effect $\left(I I_{\text {eff }}\right)$.

3.1.2 Spatial differentiation of the driving effects of population urbanization on economic growth by province in China

As shown in Figure 1, in 31 provincial administrative regions in China, the population scale effect $\left(P_{\text {eff }}\right)$, population structure effect $\left(S_{\text {eff }}\right)$ and per capita economic efficiency effect $\left(I_{\text {eff }}\right)$ on economic growth were all positive during the period of 1997-2011. The direct technical efficiency effect $\left(I I_{e f f}\right)$ and indirect structure effect $\left(I S_{\text {eff }}\right)$ on per capita economic efficiency changes were also positive. It showed that population growth, population urbanization and per capita economic efficiency improvement all had positive driving effects on economic growth.

Secondly, there were regular patterns in all the provincial administrative regions in China: $I_{\text {eff }}>S_{\text {eff }}>P_{\text {eff }}$ and $I I_{\text {eff }}>I S_{\text {eff. }}$. Almost all the contribution rates of $I_{\text {eff }}$ to economic growth were above $75 \%$ and the contribution rates of $S_{\text {eff }}$ were above $10 \%$, while the contribution rates of $P_{\text {eff }}$ were below $10 \%$. Almost all the contribution rates of $I I_{\text {eff }}$ to per capita economic efficiency changes were above $80 \%$ and the contribution rates of $I S_{\text {eff }}$ were below $20 \%$. On the whole, the comprehensive contribution rates of population urbanization to economic 
growth mainly stayed between $20 \%$ and $30 \%$ in 31 provincial administrative regions in China, which were all less than the contribution rates of the direct technical efficiency effect to economic growth.

(a)

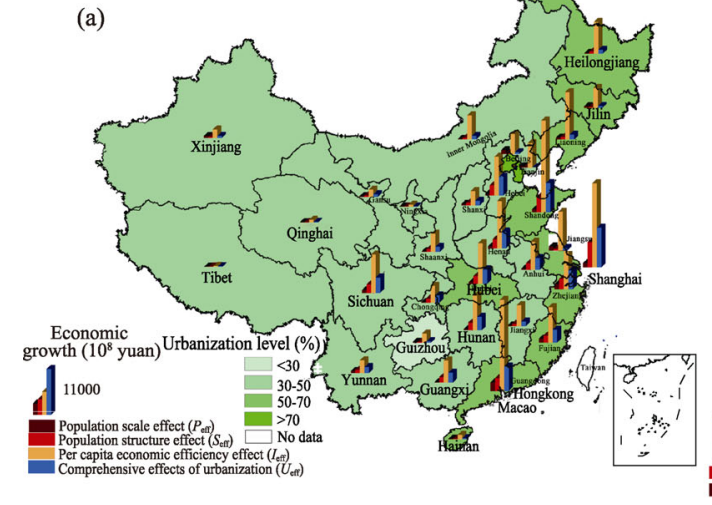

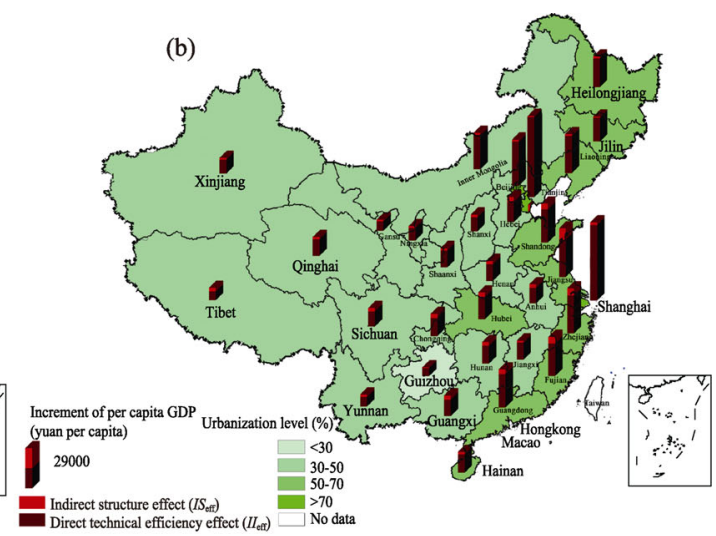

Figure 1 Driving effects of population urbanization on economic growth by province in China

Thirdly, there were obvious spatial differentiations of the driving effects of population urbanization on economic growth and per capita economic efficiency. As shown in Figure 1a, the comprehensive driving effects of population urbanization on economic growth $\left(U_{\text {eff }}\right)$ were relatively larger in most provincial administrative regions in east China, where the foundations of urbanization and economic development were better, the economic aggregates were larger and the economic growth rate and urbanization speed were faster. Central China ranked the second and west China ranked the last. However, there were some special provincial administrative regions in east China, such as Beijing, Tianjin, Shanghai and Hainan. As their economic aggregates were small and they had stepped into the mature stage of urbanization, the driving effects and contribution rates of population urbanization to economic growth were relatively smaller. Besides, as shown in Figure 1b, there were similar spatial differentiations about the driving effects of population urbanization in per capita economic efficiency.

3.1.3 Dynamic change of the driving effects of population urbanization on economic growth by province in China

The dynamic change of the driving effects of population urbanization on economic growth also varied in 31 provincial administrative regions in China (Table 2). As Beijing, Tianjin, Shanghai had stepped into the mature stage of urbanization, and the total population in some provincial administrative regions such as Liaoning, Jilin, Guizhou, Qinghai, Ningxia and Xinjiang grew too fast but the urban population grew slowly in some individual years, hence a decrease in urbanization levels. It led to negative comprehensive contribution rates of population urbanization to economic growth in these special years.

However, during the period of 1997-2011, the 31 provincial administrative regions in China were all in the accelerating or mature stages of urbanization. The growth rates of the urbanization levels were all positive in total, and the changes were relatively stable. At the same time, the economic growths were continuous and stable. Thus, the comprehensive contribution rates of population urbanization to economic growth by province in China from 1997 to 2011 were all positive in total, and the changes were relatively stable in each pro- 
vincial administrative region (Table 2). As the economic aggregate became larger and larger and the comprehensive contribution rates were relatively stable, the increments of GDP caused by population urbanization had an increasing trend in each provincial administrative region in China.

Table 2 Comprehensive contribution rates of population urbanization to economic growth by province in China from 1997 to $2011(\%)$

\begin{tabular}{|c|c|c|c|c|c|c|c|c|c|c|c|c|c|c|c|}
\hline Year & 1998 & 1999 & 2000 & 2001 & 2002 & 2003 & 2004 & 2005 & 2006 & 2007 & 2008 & 2009 & 2010 & 2011 & 1997-2011 \\
\hline China & 30.0 & 27.0 & 44.6 & 30.4 & 33.0 & 31.2 & 32.6 & 31.1 & 35.4 & 24.0 & 33.0 & 33.7 & 29.8 & 32.4 & 31.6 \\
\hline Beijing & 2.9 & 13.8 & -19.7 & -14.3 & 9.6 & 10.0 & 7.9 & 12.1 & 18.8 & 6.4 & 9.6 & 8.3 & 8.0 & 9.6 & 7.5 \\
\hline Tianjin & 4.7 & 9.5 & 4.1 & 2.6 & 3.1 & 2.7 & 2.5 & 2.7 & -0.9 & 2.2 & 2.1 & 2.1 & 2.0 & 2.1 & 2.3 \\
\hline Hebei & 28.1 & 24.8 & 48.1 & 32.7 & 43.5 & 42.9 & 40.7 & 37.6 & 17.2 & 32.7 & 39.6 & 39.6 & 33.3 & 35.3 & 35.1 \\
\hline Shanxi & 21.3 & 31.9 & 51.3 & 21.8 & 29.0 & 24.1 & 26.6 & 30.1 & 24.0 & 19.7 & 33.6 & 47.8 & 21.4 & 22.4 & 26.1 \\
\hline $\begin{array}{c}\text { Inner } \\
\text { Mongolia }\end{array}$ & 29.3 & 17.5 & 32.0 & 22.4 & 12.0 & 12.1 & 10.7 & 9.9 & 10.0 & 11.9 & 12.8 & 13.5 & 15.1 & 15.6 & 13.7 \\
\hline Liaoning & 10.5 & -6.8 & 2.4 & 3.7 & 13.0 & 11.7 & 14.4 & 16.0 & 14.0 & 8.2 & 9.1 & 9.2 & 8.6 & 9.7 & 9.8 \\
\hline Jilin & 1.9 & -13.6 & -10.5 & -4.3 & 18.6 & 13.4 & 14.7 & 15.5 & 12.4 & 6.3 & 6.6 & 7.7 & 7.8 & 7.8 & 7.8 \\
\hline Heilongjiang & 3.0 & 12.9 & 24.2 & 8.1 & 18.7 & 14.6 & 14.3 & 13.5 & 10.5 & 10.3 & 10.5 & 10.7 & 9.7 & 9.9 & 11.5 \\
\hline Shanghai & 6.6 & -21.3 & 4.1 & 29.1 & 7.7 & 0.1 & 0.0 & 0.1 & 26.8 & 4.7 & 6.2 & 6.4 & 4.6 & 5.0 & 6.3 \\
\hline Jiangsu & 34.2 & 62.4 & 73.3 & 67.7 & 26.2 & 28.5 & 25.2 & 27.2 & 19.8 & 33.4 & 36.7 & 36.0 & 33.8 & 36.4 & 34.8 \\
\hline Zhejiang & 47.7 & 48.0 & 53.7 & 19.1 & 24.4 & 23.5 & 21.6 & 29.7 & 15.0 & 21.6 & 29.1 & 31.4 & 23.7 & 29.2 & 27.0 \\
\hline Anhui & 29.3 & 35.1 & 37.9 & 12.4 & 59.7 & 54.8 & 52.3 & 14.5 & 36.5 & 28.8 & 31.7 & 31.1 & 27.9 & 29.8 & 32.6 \\
\hline Fujian & 33.7 & 36.7 & 29.1 & 27.3 & 24.8 & 24.4 & 22.9 & 25.5 & 45.1 & 24.1 & 27.0 & 27.7 & 24.4 & 26.4 & 27.9 \\
\hline Jiangxi & 17.4 & 14.8 & 53.3 & 44.0 & 36.1 & 36.0 & 33.5 & 36.4 & 4.9 & 5.8 & 5.9 & 3.3 & 19.6 & 21.8 & 19.4 \\
\hline Shandong & 9.5 & 22.2 & 18.0 & 16.8 & 19.2 & 24.3 & 28.9 & 30.6 & 27.3 & 25.8 & 29.3 & 28.4 & 27.6 & 30.0 & 26.5 \\
\hline Henan & 27.0 & 12.6 & 22.5 & 19.7 & 35.5 & 32.6 & 27.9 & 27.1 & 30.2 & 25.2 & 29.7 & 32.5 & 28.9 & 30.2 & 28.5 \\
\hline Hubei & 30.7 & 28.6 & 28.0 & 38.7 & 35.2 & 44.4 & 35.0 & 33.8 & 28.3 & 26.2 & 27.6 & 26.8 & 24.2 & 25.1 & 28.7 \\
\hline Hunan & 36.5 & 33.3 & 38.2 & 20.2 & 55.6 & 44.9 & 46.8 & 44.7 & 7.1 & 27.4 & 29.3 & 29.6 & 28.0 & 31.2 & 31.4 \\
\hline Guangdong & 29.6 & 26.1 & 11.9 & 10.4 & 19.2 & 15.1 & 16.5 & 16.6 & 19.9 & 23.2 & 29.4 & 28.9 & 21.6 & 24.1 & 21.6 \\
\hline Guangxi & 30.7 & 26.8 & 19.5 & 38.3 & 28.6 & 27.0 & 20.9 & 43.7 & 42.9 & 46.7 & 36.5 & 34.0 & 31.3 & 35.0 & 35.0 \\
\hline Hainan & 44.0 & 23.1 & 23.7 & 27.0 & 15.8 & 13.1 & 10.0 & 8.3 & 45.4 & 13.6 & 19.4 & 16.4 & 12.5 & 16.2 & 18.5 \\
\hline Chongqing & 32.5 & 26.4 & 67.6 & 53.2 & 32.8 & 31.4 & 31.1 & 28.8 & 56.4 & 30.0 & 31.8 & 30.5 & 26.7 & 27.2 & 32.7 \\
\hline Sichuan & 19.7 & 32.6 & 35.1 & 25.9 & 35.8 & 39.6 & 34.6 & 42.8 & 35.5 & 27.9 & 35.3 & 28.0 & 27.0 & 27.1 & 31.1 \\
\hline Guizhou & 2.7 & 5.0 & 14.4 & 14.5 & 19.4 & 25.2 & 19.2 & 24.2 & -2.5 & 12.1 & 15.7 & 15.7 & 14.3 & 12.6 & 13.8 \\
\hline Yunnan & 37.6 & 49.9 & 67.8 & 37.3 & 38.9 & 35.3 & 40.4 & 38.1 & 25.4 & 29.7 & 33.4 & 29.8 & 29.5 & 27.0 & 33.2 \\
\hline Tibet & 61.2 & 66.9 & 68.1 & 73.5 & 54.2 & 48.2 & 38.3 & 32.5 & 29.3 & 28.0 & 22.0 & 45.0 & 45.3 & 44.0 & 42.5 \\
\hline Shaanxi & 39.1 & 29.5 & 55.4 & 30.6 & 33.6 & 34.3 & 20.7 & 25.9 & 10.9 & 20.2 & 19.6 & 23.0 & 21.6 & 22.4 & 23.6 \\
\hline Gansu & 19.8 & 17.2 & 38.3 & 26.9 & 28.2 & 46.3 & 27.0 & 27.2 & 37.3 & 19.5 & 27.6 & 27.1 & 24.1 & 22.9 & 27.2 \\
\hline Qinghai & 19.0 & -9.6 & -17.9 & 55.7 & 21.7 & 17.9 & 13.6 & 22.7 & 36.9 & 17.8 & 17.8 & 23.0 & 15.8 & 17.7 & 19.7 \\
\hline Ningxia & 18.4 & 8.5 & -13.9 & 2.1 & 35.1 & 32.3 & 33.7 & 32.8 & 14.7 & 18.5 & 18.6 & 19.5 & 17.4 & 19.1 & 19.5 \\
\hline Xinjiang & -9.9 & 6.0 & -12.3 & -9.8 & 19.6 & 19.4 & 25.5 & 19.1 & 19.2 & 18.7 & 20.6 & 26.8 & 21.2 & 19.0 & 17.2 \\
\hline
\end{tabular}




\subsection{Spatiotemporal characteristics of the driving effects of China's popula- tion-economic urbanization on water use change}

3.2.1 The driving effects of China's population-economic urbanization on total water use change and water use economic efficiency

As shown in Table 3, during the period of 1997-2011, the economic scale effect $\left(E P_{\text {eff }}\right)$ caused $7399 \times 10^{8} \mathrm{~m}^{3}$ of water use increase in China on the whole. However, the water use economic efficiency effect $\left(E I_{\text {eff }}\right)$ and the direct economic urbanization effect $\left(E S_{\text {eff }}\right)$ caused $4081 \times 10^{8} \mathrm{~m}^{3}$ and $2888 \times 10^{8} \mathrm{~m}^{3}$ of water use decrease respectively. Thus, water use in China increased $429 \times 10^{8} \mathrm{~m}^{3}$. Specifically, the indirect economic urbanization effect through influencing water use efficiency $\left(E S I_{e f f}\right)$ caused $1641 \times 10^{8} \mathrm{~m}^{3}$ of water use decrease. Thus, The direct and indirect driving effect of economic urbanization $\left(E U_{\text {eff }}\right)$ caused $4530 \times 10^{8} \mathrm{~m}^{3}$ of water use decrease. As the population urbanization effect through influencing economic scale $\left(Q E P_{\text {eff }}\right)$ caused $2352 \times 10^{8} \mathrm{~m}^{3}$ of water use increase, the population-economic urbanization caused $2177 \times 10^{8} \mathrm{~m}^{3}$ of water use decrease in total.

Table 3 Driving effects of population-economic urbanization on water use change in China from 1997 to 2011

\begin{tabular}{cccccccccccccccc}
\hline Year & 1998 & 1999 & 2000 & 2001 & 2002 & 2003 & 2004 & 2005 & 2006 & 2007 & 2008 & 2009 & 2010 & 2011 & $1997-2011$ \\
\hline$\Delta W$ & -131 & 155 & -93 & 70 & -70 & -256 & 225 & 75 & 162 & 11 & 77 & 72 & 40 & 93 & 429 \\
$E P_{\text {eff }}$ & 415 & 405 & 449 & 441 & 482 & 514 & 515 & 590 & 672 & 758 & 530 & 514 & 585 & 529 & 7399 \\
$E I_{\text {eff }}$ & -391 & -77 & -325 & -174 & -330 & -514 & -166 & -312 & -251 & -392 & -306 & -263 & -326 & -255 & -4081 \\
$E S_{\text {eff }}$ & -155 & -173 & -217 & -198 & -221 & -256 & -124 & -204 & -260 & -355 & -147 & -179 & -219 & -181 & -2888 \\
$E S I_{\text {eff }}$ & -111 & -53 & -130 & -93 & -133 & -171 & -71 & -123 & -127 & -186 & -99 & -106 & -131 & -106 & -1641 \\
$E U_{\text {eff }}$ & -266 & -226 & -348 & -290 & -354 & -427 & -195 & -327 & -387 & -541 & -246 & -285 & -350 & -287 & -4530 \\
$Q E P_{\text {eff }}$ & 125 & 109 & 200 & 134 & 159 & 160 & 168 & 184 & 238 & 182 & 175 & 173 & 175 & 171 & 2352 \\
$\Delta W U$ & -141 & -117 & -147 & -156 & -195 & -267 & -27 & -143 & -150 & -359 & -72 & -112 & -176 & -115 & -2177 \\
$\Delta E I$ & -70.3 & -29.8 & -60.0 & -37.9 & -51.8 & -66.0 & -22.6 & -36.3 & -32.0 & -41.3 & -22.4 & -20.0 & -22.5 & -16.4 & -529.2 \\
$E I I_{\text {eff }}$ & -50.3 & -9.2 & -36.0 & -17.7 & -31.0 & -44.1 & -12.9 & -21.9 & -15.7 & -21.7 & -15.1 & -11.9 & -13.4 & -9.6 & -310.6 \\
$E I S_{\text {eff }}$ & -20.0 & -20.6 & -24.0 & -20.2 & -20.8 & -22.0 & -9.7 & -14.3 & -16.3 & -19.6 & -7.3 & -8.1 & -9.0 & -6.8 & -218.7 \\
\hline
\end{tabular}

Note: The units of $\Delta W, E P_{\text {eff }}, E I_{\text {eff }}, E S_{\text {eff }}, E S I_{\text {eff }}, E U_{\text {eff, }}, Q E P_{\text {eff }}$, and $\Delta W U$ are $10^{8} \mathrm{~m}^{3}$, the units of $\Delta E I, E I I_{e f f}$, and $E I S_{\text {eff }}$ are $\mathrm{m}^{3}$ per 10,000 yuan.

As shown in Table 3, in each year whether $\Delta W>0$ or $\Delta W<0$, the direct, indirect and comprehensive effects of economic urbanization on water use change, which is marked as $E S_{\text {eff, }}$ $E S I_{\text {eff }}$, and $E U_{\text {eff }}$ respectively, were all negative. It means that economic urbanization had a decrement effect on water use growth in China because it can optimize the industrial structure and improve the water use efficiency. However, population urbanization in China caused all $Q E P_{\text {eff }}$ values to be positive every year. It means that population urbanization had an increment effect on water use growth in China because it can promote economic growth. To sum up, population-economic urbanization in China had a decrement effect on water use growth as all the $\Delta W U$ values were negative over years.

In addition, as the direct technical efficiency effect $\left(E I I_{\text {eff }}\right)$ and indirect economic urbanization effect $\left(E I S_{\text {eff }}\right)$ were all negative, water use per 10,000 yuan GDP in China decreased year by year $(\Delta E I<0)$. It means that economic urbanization had an increment effect on pro- 
moting water use efficiency. From 1997 to 2011, water use per 10,000 yuan GDP in China had decreased $529.2 \mathrm{~m}^{3}$ per 10,000 yuan in total. The direct technical efficiency effect $\left(E I I_{\text {eff }}\right)$ had decreased $310.6 \mathrm{~m}^{3}$ per 10,000 yuan, and the contribution rate was $58.7 \%$. The indirect economic urbanization effect $\left(E I S_{\text {eff }}\right)$ had decreased $218.7 \mathrm{~m}^{3}$ per 10,000 yuan, and the contribution rate was $41.3 \%$. From then on, the contribution rates of economic urbanization to water use efficiency improvement have been relatively stable. It showed that economic urbanization was an important way to promote water use efficiency in China.

3.2.2 Spatial differentiation of the driving effects of population-economic urbanization on water use change by province in China

During the period of 1997-2011, except in Beijing, Tianjin, Hebei, Liaoning, Zhejiang, Henan, Guangxi and Ningxia, the total water use changes $(\Delta W)$ in other provincial administrative regions were all positive in total. As shown in Figure 2, the economic scale effects of urbanization $\left(E P_{e f f}\right)$ in 31 provincial administrative regions were all positive. The direct and indirect effects of economic urbanization $\left(E S_{\text {eff }}\right.$ and $\left.E I_{\text {eff }}\right)$ were all negative. This kind of phenomenon was similar to the whole country.

(a) Direct effect of economic urbanization $E S_{\text {eff }}$

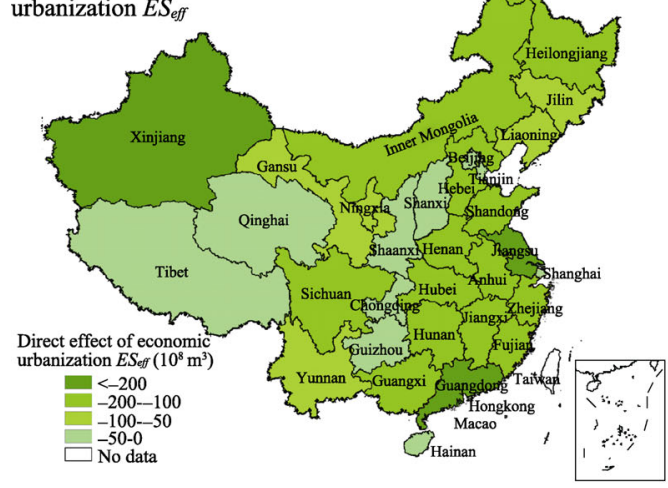

(c) Economic scale effect of urbanization $Q E P_{\text {eff }}$

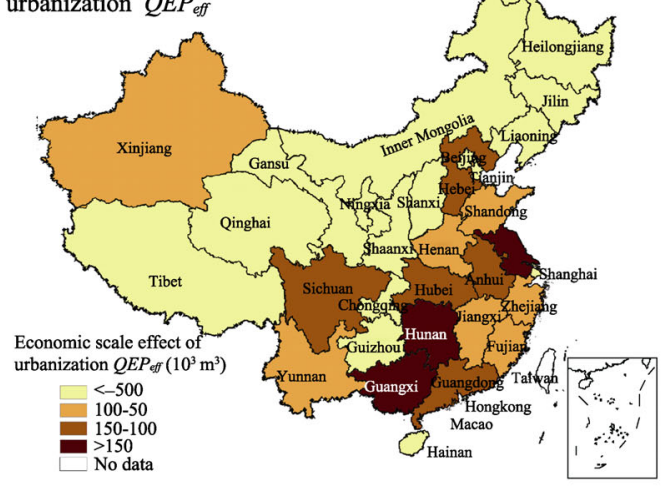

(b) Efficiency effect of economic

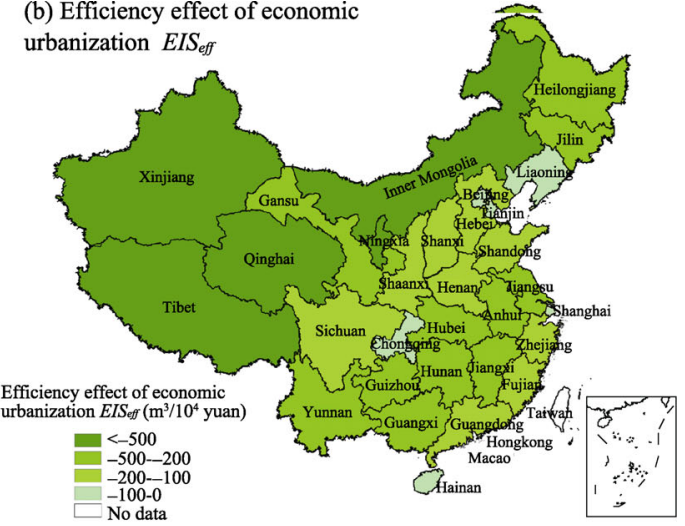

(d) Comprehensive driving effect of urbanization $\triangle W U$

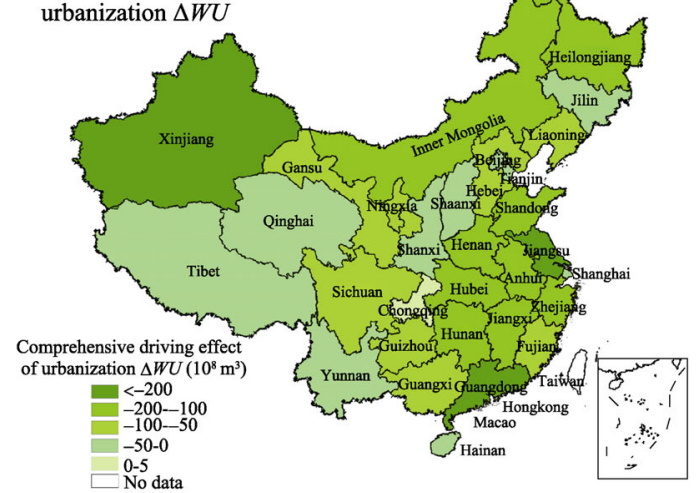

Figure 2 Driving effects of population-economic urbanization on water use change by province in China

As for the direct decrement effects of economic urbanization $\left(E S_{\text {eff }}\right)$, the decreasing amounts of water use were generally between $10-20$ billion $\mathrm{m}^{3}$ in most provincial administrative regions in east and central China which had large population and economic aggregate 
and stepped into the accelerating period of urbanization. However, the decreasing amounts of water use were generally below 10 billion $\mathrm{m}^{3}$ in most provincial administrative regions in west China which had small population and economic aggregate, and in some provincial administrative regions in east China which stepped into the mature stage of urbanization. The decreasing amounts of water use were the largest in Jiangsu, Xinjiang and Guangdong, which are all more than 20 billion $\mathrm{m}^{3}$. The decreasing amounts of water use were the least in ten provincial administrative regions such as Hainan, Tianjin, Beijing and so on, which are all below 5 billion $\mathrm{m}^{3}$ (Figure $2 \mathrm{a}$ ).

The spatial distribution of the efficiency effects of economic urbanization $\left(E I S_{\text {eff }}\right)$ was different from that of $E S_{\text {eff. }}$ The decreasing amounts of water use per 10,000 GDP were larger in most provincial administrative regions in west and central China where the water use efficiency was low and the urbanization speed was high. For example, the decreasing amounts of water use per 10,000 GDP in Tibet, Ningxia Xinjiang, Inner Mongolia and Qinghai were all above $500 \mathrm{~m}^{3}$ per 10,000 yuan, while in Shanghai, Tianjin, Beijing, Chongqing, Liaoning and Hainan, where the water use efficiency was high and the urbanization speed was low, the decreasing amounts of water use per 10,000 GDP were all below 50 $\mathrm{m}^{3}$ per 10,000 yuan (Figure $2 \mathrm{~b}$ ).

On the other hand, the population urbanization effects on total water use change through influencing economic scale $\left(Q E P_{\text {eff }}\right)$ were also different in 31 provincial administrative regions in China (Figure 2c). Generally, in those provincial administrative regions with large population and economic aggregate, high urbanization speed and low water use efficiency, the increment effects of population urbanization on economic growth were relatively large, and the increment effects of population urbanization on total water use $\left(Q E P_{\text {eff }}\right)$ were also large. However, in most provincial administrative regions in east China, though they had large population and economic aggregate, they usually had high water use efficiency. Thus, the increment effects of population urbanization on total water use $\left(Q E P_{\text {eff }}\right)$ were not very large compared to those in central and west China. Nevertheless, the economic scale effects of population urbanization $\left(Q E P_{\text {eff }}\right)$ in the east and central China were relatively large on the whole while those in west China and Beijing, Tianjin, Shanghai were relatively small.

To sum up, the comprehensive driving effects of population-economic urbanization on total water use change $(\Delta W U)$ in 31 provincial administrative regions in China were all below zero except in Chongqing (Figure 2d). It means that the increment effects of population urbanization on total water use $\left(Q E P_{\text {eff }}\right)$ were smaller than the decrement effects of economic urbanization on total water use $\left(E U_{\text {eff }}\right.$, the sum of $E S_{\text {eff }}$ and $\left.E S I_{\text {eff }}\right)$. That's to say, the population-economic urbanization did not increase China's total water use. Moreover, it can decrease China's total water use as long as China focuses on the optimization of industrial structure and the promotion of water use efficiency.

3.2.3 Dynamic change of the driving effects of population-economic urbanization on water use change by province in China

The dynamic change of the driving effects of population-economic urbanization on water use change also varied in 31 provincial administrative regions in China (Table 4). In some provincial administrative regions and some individual years, the primary industry developed fast while the secondary and tertiary industries developed slowly, the economic urbanization 
Table 4 Comprehensive contributions of population-economic urbanization on water use change by province in China from 1997 to $2011\left(10^{8} \mathrm{~m}^{3}\right)$

\begin{tabular}{|c|c|c|c|c|c|c|c|c|c|c|c|c|c|c|c|}
\hline & & 99 & 000 & 001 & 002 & 003 & 2004 & 2005 & 2006 & 2007 & 2008 & 2009 & 2010 & \multicolumn{2}{|c|}{$20111997-201$} \\
\hline Ching & & 117 & 147 & 156 & 195 & -267 & -27 & -143 & -150 & -359 & -72 & -112 & -176 & -115 & -2177 \\
\hline & & & & & & & & & & & & & & & \\
\hline Tianjin & & 28 & 15 & 11 & 00 & 14 & 14 & -1.7 & -2.3 & -2.4 & -2.7 & -2.2 & -2.6 & 20 & \\
\hline & & & & & & & & & -13.0 & -11.4 & -5.2 & -6.8 & -10.3 & -7.3 & \\
\hline Shanxi & 21 & 3.3 & 8.7 & -21 & 3.2 & -2.2 & -2.9 & -5.0 & -1.5 & -5.9 & -1.9 & 0.6 & 1.6 & -8.1 & -10.0 \\
\hline $\begin{array}{c}\text { Inner } \\
\text { Mongolia }\end{array}$ & & .J & -5.0 & -8.7 & 12.6 & -20.9 & -12.5 & -24.1 & -20.3 & -22.1 & -16.5 & -18.0 & -13.6 & -11.8 & -177.3 \\
\hline Liaon & & & -13.7 & -3.1 & -1.0 & -4.1 & -4.3 & -3.9 & -6.1 & -12.3 & -8.3 & -11.4 & -9.7 & -6.6 & -79.9 \\
\hline & & -7.4 & 29.7 & -6.7 & 12 & -3.9 & 28 & -0.6 & -6.8 & -12.4 & -5.4 & -5.4 & -5.9 & 66 & -28.5 \\
\hline Teilo & .7 & -12.4 & -21.2 & -2.0 & -1.9 & -16.8 & 5.6 & -4.4 & -6.4 & -18.5 & -8.8 & -11.4 & -17.2 & -11.5 & \\
\hline & & & -1.6 & 1.3 & 00 & -2.2 & -4.4 & -5.9 & 0.0 & -3.1 & -1.9 & -1.8 & -4.3 & 20 & \\
\hline & -24.8 & 7.6 & 8.3 & 9.1 & -17.5 & -39.0 & -37.3 & -26.3 & -21.6 & -20.4 & -12.1 & -12.4 & -13.6 & -11.4 & \\
\hline & & -2.9 & -1.5 & -6.3 & -8.0 & -13.2 & -11.3 & -9.9 & -12.7 & -12.2 & -4.7 & -5.7 & -7.7 & -5.0 & \\
\hline Anhui & -8.1 & 4.8 & -8.9 & -51.0 & 2.1 & -9.8 & 3.4 & -12.3 & -9.2 & -11.2 & -18.7 & 2.9 & -13.0 & -12.3 & \\
\hline & & & -7.0 & -0.0 & -0.0 & & -0.0 & -6.0 & -5.6 & -8.0 & -5.8 & -5.0 & 9.1 & -3.0 & \\
\hline Jiangxi & -20.2 & -0.4 & 5.8 & -3.0 & -6.2 & -11.4 & -5.8 & -2.8 & $-1-.6$ & -112.2 & -16.5 & -17.1 & -15.8 & 16.2 & \\
\hline Shan & & -9.6 & -14.8 & -9.9 & -17.3 & -16.2 & -11.1 & -14.1 & -7.0 & -17.4 & -9.4 & -11.3 & -12.0 & -9.3 & \\
\hline & & -0.1 & -8.1 & -9.4 & -5.7 & -21.4 & 5.1 & -5.4 & -66.2 & -14.8 & -1.3 & -4.8 & -9.5 & -8.1 & \\
\hline & & -11.0 & -1.4 & -4.5 & -10.4 & 2.2 & -0.7 & -4.3 & -7.1 & -10.3 & -4.7 & -7.2 & -11.1 & -3.2 & \\
\hline & & -6.6 & -6.9 & -11.1 & -9.1 & -4.1 & 2.3 & -2.5 & -20.7 & & -12.6 & -12.8 & -15.5 & & \\
\hline & 11.4 & -10.1 & -29.7 & -18.2 & -18.3 & -32.3 & -25.4 & -24.2 & -24.5 & -25.0 & -11.2 & -6.1 & -16.5 & -11.3 & \\
\hline & & & 1.5 & -6.9 & -2.6 & -14.0 & -9.8 & 1.7 & -6.0 & -9.6 & -9.6 & -12.6 & -14.6 & & \\
\hline & & . & 1.8 & 1.5 & 0.5 & -0.2 & -0.9 & -2.2 & 0.6 & -2.9 & -0.5 & -1.6 & -3.6 & -2.0 & \\
\hline Chor & & & 1.1 & 0.6 & 0.0 & & 0.3 & 0.1 & 0.0 & 1.5 & & 0.8 & 0.3 & & \\
\hline & & -0.0 & -7.2 & -0.1 & -3.4 & -2.5 & -3.0 & 2.1 & -8.4 & -10.9 & -6.7 & -4.9 & -10.0 & -11.0 & \\
\hline & & -2.9 & -3.0 & -3.1 & -2.9 & -1.6 & -2.6 & -2.5 & -6.1 & -6.8 & -1.8 & -3.9 & -4.4 & -9.1 & \\
\hline & & & 4.0 & -1.5 & -2.5 & -1.6 & -3.2 & -0.5 & -4.2 & -4.7 & -0.3 & -5.7 & -7.6 & -5.8 & \\
\hline & & & 1.3 & -0.4 & 2.5 & -2.1 & -8.3 & -3.9 & -1.1 & -1.7 & -1.2 & -2.8 & -15.1 & -2.5 & \\
\hline Shaan & & -5.4 & -0.3 & -3.3 & -2.2 & -2.3 & -0.1 & -1.9 & -3.4 & -6.6 & -4.3 & -5.1 & -5.2 & -3.7 & \\
\hline & & -7.5 & -4.4 & -0.2 & -0.1 & -1.6 & -1.1 & -3.0 & -11.7 & -7.4 & -1.4 & -4.5 & -5.3 & -5.7 & -57.2 \\
\hline Qinghai & 1.2 & -1.6 & -2.3 & -0.3 & -1.1 & -0.0 & -1.7 & -1.3 & -0.8 & -2.2 & -0.6 & -1.3 & -1.5 & -1.9 & -19.2 \\
\hline & & -4.8 & -15.4 & -4.7 & -2.2 & -8.1 & -12.2 & -1.1 & -5.3 & -5.1 & -3.0 & -3.3 & -4.1 & -4.2 & -69.9 \\
\hline Xinjiang & -3.7 & 56.9 & -29.0 & -32.7 & -15.9 & -9.5 & -24.7 & -19.8 & -24.2 & -23.4 & -20.0 & -14.2 & -31.0 & -26.4 & -331.4 \\
\hline
\end{tabular}

levels might decrease. Or even though the economic urbanization levels increased, they increased a little. Thus, the decrement effects of economic urbanization on total water use $\left(E U_{\text {eff }}\right)$ were smaller than the economic scale effects of population urbanization on total water use $\left(Q E P_{\text {eff }}\right)$. Therefore, the comprehensive contributions of population-economic urbanization to water use change were positive in some individual years. However, during the period of 1997-2011, all the 31 provincial administrative regions in China were in the accelerating or mature stage of urbanization. The population-economic urbanization levels did not fluctuate greatly. Thus, in most provincial administrative regions and most years, the comprehensive contributions of population-economic urbanization to water use change were negative. Moreover, the decrement effects of population-economic urbanization on total water use were relatively stable in time. 


\section{Conclusions}

(1) Population urbanization can promote the economic growth directly and indirectly through optimizing the structure of urban-rural population and improving the economic efficiency per capita. However, this kind of effect should not be overstated. From 1997 to 2011, the direct contribution rates of population urbanization to economic growth were mainly between $15 \%-20 \%$, and the comprehensive contribution rates were around $30 \%$ over years. Without counting the influence of population growth, more than $60 \%$ of economic growth in China relied on the improvement of the direct technical efficiency effect. Therefore, during the process of promoting the New Urbanization Strategy in China, such idea as urbanization is the engine or major driving force of economic growth should be properly weakened. China should pay more attention to the comprehensive meaning of urbanization, promote China's social progress and improve China's resources and environmental efficiency. Moreover, China should focus more on how to promote a continuous and steady economic growth through the improvement of direct technical efficiency effect.

(2) The population-economic urbanization has positive and negative impacts on China's total water use growth at the same time. From 1997 to 2011, the population-economic urbanization increased $2352 \times 10^{8} \mathrm{~m}^{3}$ of water use by increasing the economic aggregate. However, it decreased $4530 \times 10^{8} \mathrm{~m}^{3}$ of water use by optimizing the industrial structure and improving the water use efficiency. Thus, it decreased $2177 \times 10^{8} \mathrm{~m}^{3}$ of water use in total. On the whole, the population-economic urbanization had obvious decrement effects on China's total water use and water use per 10,000 yuan GDP. It was one of the most important ways to promote water use efficiency and inhibit water use growth in China. Another important way was the direct technical efficiency effect. It decreased $2440 \times 10^{8} \mathrm{~m}^{3}$ of water use in total. Therefore, the population-economic urbanization was not the cause of water use growth in China. The major cause of water use growth was the population and economic scale effect. It increased $5046 \times 10^{8} \mathrm{~m}^{3}$ of water use in China, without counting the economic scale effect caused by population urbanization on water use growth.

(3) The relationships among urbanization, economic growth and water use change in 31 provincial administrative regions were similar to the whole country. Moreover, they had obvious spatiotemporal differentiations. Generally, most provincial administrative regions in east and central China had large population and economic aggregate and stepped into the accelerating period of urbanization. Thus, the increment effects of population urbanization on economic growth were relatively large. The increment effects on total water use were also large and had an increasing trend year by year. However, the decrement effects of economic urbanization on total water use by industrial structure optimization and water use efficiency improvement were also large at the same time. To sum up, the population-economic urbanization had negative effects on water use growth in most provincial administrative regions in China, and the spatiotemporal differences among them were lessened during the period of 1997-2011.

(4) Though the population-economic urbanization helps to decrease water use for China and most provincial administrative regions, it can make population and industries concentrate in urban built-up areas or urban agglomerations rapidly. In this kind of urban regions, the population-economic urbanization levels are very high and even up to $100 \%$. Thus, the economic growth and water use change are mainly decided by the population-economic 
scale effects and the direct technical efficiency effects. However, in a relatively short time, technical progresses are limited. Thus, the population-economic urbanization usually leads to rapid water use growth in urban built-up areas or urban agglomerations, and then causes water crisis. Therefore, China should construct the water transfer and compensation mechanisms between urban and rural areas (or low and high density urban areas), under the background of slow or negative growth of total water use in China or in a relatively large area (Bao and Fang, 2012).

\section{References}

Ang B W, Zhang F Q, 2000. A survey of index decomposition analysis in energy and environmental studies. Energy, 25(12): 1149-1176.

Bao C, 2012. Driving effects of water use change in oasis cities based on the urbanization perspective. Arid Land Geography, 35(6): 988-995. (in Chinese)

Bao C, Fang C L, 2006. Study on the quantitative relationship between urbanization and water resources utilization in the Hexi Corridor. Journal of Natural Resources, 21(2): 301-310. (in Chinese)

Bao C, Fang C L, 2007. Water resources constraint force on urbanization in water deficient regions: A case study of the Hexi Corridor, arid area of NW China. Ecological Economics, 62(3/4): 508-517.

Bao C, Fang C L, 2009. Integrated assessment model of water resources constraint intensity on urbanization and its application in arid area. Journal of Geographical Sciences, 19(2): 273-286.

Bao C, Fang C L, 2010. Interaction mechanism and control modes on urbanization and water resources exploitation and utilization. Urban Studies, 17(12): 19-23. (in Chinese)

Bao C, Fang C L, 2012. Water resources flows related to urbanization in China: Challenges and perspectives for water management and urban development. Water Resources Management, 26(2): 531-552.

Bertinelli L, Black D, 2004. Urbanization and growth. Journal of Urban Economics, 56(1): 80-96.

Brown L R, 2001. How water scarcity will shape the new century. Water Science and Technology, 43(4): 17-22.

Chen A P, Partridge M D, 2013. When are cities engines of growth in China? Spread and backwash effects across the urban hierarchy. Regional Studies, 47(8): 1313-1331.

Fang C L et al., 2009. Report on China's Urbanization and the Guarantee of Resources and Eco-environment. Beijing: Science Press. (in Chinese)

Jenerette G D, Larsen L, 2006. A global perspective on changing sustainable urban water supplies. Global and Planetary Change, 50(3/4): 202-211.

Jia S F, Zhang S F, Yang H et al., 2004. Relation of industrial water use and economic development: Water use Kuznets Curve. Journal of Natural Resources, 19(3): 279-284. (in Chinese)

Lin X Q, Wang D, Ren W B et al., 2013. Research on the mechanism of urbanization to economic increase in China. Geographical Research, 32(4): 691-700. (in Chinese)

Liu J X, Wang Q, Sun P et al., 2008. Decomposition effect on China's annual ecological footprints variation from 1990 to 2004. Journal of Natural Resources, 23(1): 61-68. (in Chinese)

Liu Y B, Li R D, Song X F, 2005. Grey associative analysis of regional urbanization and eco-environment coupling in China. Acta Geographica Sinica, 60(2): 237-247. (in Chinese)

Merrett S, 1997. Introduction to the Economics of Water Resources: An International Perspective. UCL Press.

Shen J F, 2006. Estimating urbanization levels in Chinese provinces in 1982-2000. International Statistical Review, 74(1): 89-107.

Song J J, Zhang Q J, Liu Y Q, 2004. Analysis and suggestions on water resources security in 2020 in China. China Water Resources, (9): 14-17. (in Chinese)

Sun C Z, Wang Y, 2010. Decomposition of driving effects for industrial water utilization change and spatial temporal difference in Liaoning Province. Geographical Research, 29(2): 244-252. (in Chinese)

Sun J W, 1998. Changes in energy consumption and energy intensity: A complete decomposition model. Energy Economics, 20(1): 85-100.

Zhang Q, Wang B D, Cao M L, 2011. Analysis of water resource utilization change based on factor decomposition model. Journal of Natural Resources, 26(7): 1209-1216. (in Chinese)

Zhou Y X, 1995. Urban Geography. Shanghai: The Commercial Press. (in Chinese)

Zhou Y X, Yu H B, 2002. Suggestions on reconstructing the urbanization levels in China based on the fifth population census. Statistical Research, (4): 44-47. (in Chinese) 